\title{
The association between hydration status and cognitive function among free-living elderly volunteers
}

\author{
Agata Białecka-Dębek ${ }^{1}$ (D) Barbara Pietruszka ${ }^{1}$ (D)
}

Received: 28 February 2018 / Accepted: 3 August 2018 / Published online: 20 August 2018

(c) The Author(s) 2018

\begin{abstract}
Background Ageing is inevitably associated with a progressive cognitive decline. With the rising percentage of the elderly in society, the number of people with dementia and cognitive impairment increases. Water is a vital ingredient that must be included in the diet. The impact of hydration status on cognitive performance has been studied only a little so far.

Aims The objective of the study was to investigate the relation between the hydration status and the cognitive function. Methods The study was conducted among 60 free-living volunteers, aged 60-93 years. Data on water consumption were gathered based on 3-day records. The hydration status was assessed in morning urine samples by evaluating urine specific gravity. The cognitive function was tested using the Mini Mental State Examination (MMSE), the Babcock Story Recall Test and the Trail Making Test. Information about depression was gathered by the Geriatric Depression Scale.

Results The mean daily total water intake was $2441 \pm 622 \mathrm{ml}$, and $70 \%$ of respondents met the reference values for an adequate intake. The mean urine specific gravity $\left(1.013 \mathrm{~g} / \mathrm{cm}^{3}\right.$, range of $\left.1.004-1.025 \mathrm{~g} / \mathrm{cm}^{3}\right)$ indicated that most of the individuals were in a good hydration state. The average result of MMSE was 27.8, which is connected with mild cognitive impairment. There was no significant relationship between the hydration status and the results of the cognitive function test in the studied population.

Discussion/conclusion As the elderly volunteers had a good hydration status, there was no significant relationship between cognitive performance and urine specific gravity. It is necessary to replicate the findings of this study with a larger and more diverse sample of older adults.
\end{abstract}

Keywords Urine specific gravity $\cdot$ Hydration $\cdot$ Cognitive test $\cdot$ Cognitive function $\cdot$ Elderly

\section{Introduction}

Water is a major component of the human body, and its amount varies depending on the body composition, i.e. proportion of muscle mass and fat tissue [1]. In the elderly, water accounts for approximately $50 \%$ of the body weight. As it is a crucial substance for the metabolism, it plays a role as medium of biochemical reactions, in circulation (blood, lymph), substrate transport across membranes, temperature regulation, fluid-electrolyte turnover, and internal environment homeostasis [2]; even mild dehydration is an undesirable condition.

Agata Białecka-Dębek

agata_bialecka_debek@sggw.pl

1 Department of Human Nutrition, Warsaw University of Life Sciences, Nowoursynowska 159c, 02-776 Warsaw, Poland
Dehydration can be a result of pathologic fluid loss, diminished water intake, or both of those reasons occurring simultaneously. The elderly are at a higher risk of dehydration than younger adults because of several changes in the organism during ageing, such as a diminished sensation of thirst, lower ability of urine concentration, and sarcopenia (diminished muscle mass, which causes a smaller fluid reserve). Moreover, polypharmacy is a factor, which can increase fluid loss among the elderly, especially when medicines such as diuretics and laxatives are taken [3, 4]. A limited fluid intake may also be related to a number of other factors, including physical limitations, such as reduced mobility or incontinence, social isolation or dementia, as well as other illnesses [5].

Chronic dehydration causes fluid deficits within cells, which can affect the absorption of medications. Any decrease in the stored body water lowers the plasma volume, which can then decrease the stroke volume and force 
the body to compensate by raising the heart rate. A lower plasma volume has an impact on sweating and blood flow to the skin and, therefore, impedes thermoregulation [6]. Initial symptoms of dehydration are headaches, fatigue and general malaise. Failure of further consumption of sufficient amounts of water leads to the deterioration of cognitive and neurologic functions, organ failure (renal), and in extreme cases_death [7].

On the other hand, cognitive impairment of the elderly, including dementia, is the reason for a decreased probability to meet self-care needs, including a proper fluid intake [8]. Cognitive functioning in the elderly is associated with many factors, mainly with gender, age and educational level. In addition, lifestyle (smoking, alcohol consumption, physical inactivity) and a lack of social support are also related to decline of cognitive function [9].

A result of dehydration is a worse quality of life; therefore, prevention, early identification and treatment are very important. There is a lot of information on dehydration among hospitalised and institutionalised elderly, but we only have a small amount of information on the situation in seemingly healthy elderly. Hence, the aim of the study was to investigate the relation between the hydration status and the cognitive functions among a chosen group of seemingly healthy elderly.

\section{Methods}

The cross-sectional study was conducted in Warsaw (Poland), among 60 free-living (noninstitutionalised) volunteers, aged 60 years and older. Information about opportunities to participate in the study was distributed by leaflets and was published in the local paper. The study protocol was approved on the 10th of January 2014 by the ethical commission of the National Food and Nutrition Institute in Warsaw, Poland.

Inclusion criteria were age 60 and above; noninstitutionalised; ability to sign an informed consent to participate in the study. Exclusion criteria included diagnosed neurodegenerative disease or depression, or being treated with antidepressants; BMI below $18.5 \mathrm{~kg} / \mathrm{m}^{2}$; taking corticosteroids, diuretics; vomiting, diarrhoea or fever within the past 3 days; cancer; cardiac failure and acute or chronic renal failure.

\section{Basic measurements}

General information about the respondents was collected with the use of the questionnaire method. The questionnaire contained questions about the socio-economic status, information on the educational level, health status and medical history, selected parameters of lifestyle (smoking, alcohol consumption, dietary supplements usage, self-reported physical activity level), as well as information about feelings of thirst, such as the level of the sense of thirst, dryness in the mouth and refreshed feeling after a drink. The respondents were also asked about the presence of dehydration symptoms (headaches, dizziness, weakness), and situations associated with reducing the amount of fluid intake, such as urinary incontinence, difficulty in using the toilet [10].

Body weight was measured on a calibrated digital scale (Seca 213, Germany) in $\mathrm{kg}$ with an accuracy of $0.1 \mathrm{~kg}$. The respondents were asked to stay in light clothing and take their shoes off. Their height was assessed to the nearest $0.1 \mathrm{~cm}$ with the use of a portable stadiometer (Seca 2013, Germany). The body mass index (BMI) was calculated according to the equation: $\mathrm{BMI}=$ weight $(\mathrm{kg}) /$ height $(\mathrm{m})^{2}$. According to WHO [11], a BMI below $18.5 \mathrm{~kg} / \mathrm{m}^{2}$ means malnutrition, from 18.5 to $24.9 \mathrm{~kg} / \mathrm{m}^{2}$ —normal body weight, from 25.0 to $29.9 \mathrm{~kg} / \mathrm{m}^{2}$-overweight, and over $30.0 \mathrm{~kg} /$ $\mathrm{m}^{2}$-obesity.

The blood pressure measurement was done using the standard procedure in a sitting position with the use of an automatic blood pressure monitor (Omron M2 Basic).

\section{Dietary assessment}

Data on food intake were gathered during three non-consecutive days ( 2 weekdays, and 1 weekend day) with the use of the 3-day food record method. Individuals received detailed written information on how to fill the questionnaire properly. The portion sizes were gathered for beverages in $\mathrm{ml} /$ days and for solid foods in g/days. All participants received a digital kitchen scale (with a precision of $1 \mathrm{~g}$ ). The diet records were complemented with dietitian interviews. The daily water intake and the energy value of the diets were calculated with the use of the Dieta 5. software, which contained a food database by Kunachowicz et al. [12]. The daily water consumption was compared with reference values for an adequate intake $(\mathrm{AI}=2000 \mathrm{ml}$ for women and $2500 \mathrm{ml}$ for men) [13].

\section{Hydration status}

The hydration status was tested by measuring urine specific gravity. Each respondent received a plastic container for the urine sample with an individual code. Individuals were asked to bring the urine sample for the next meeting and were informed on how to collect urine (portion of morning urine, a volume of approximately $50 \mathrm{ml}$ ). Urine specific gravity was measured using a urometer (Spółdzielnia Rzemieślnicza 'Żoliborz', Poland). The urine was poured into a narrow cylinder of $50 \mathrm{ml}$ volume; then, the urometer was placed inside the cylinder. After the cessation of urometer fluctuations, the relative weight of urine was determined to the bottom meniscus. The measurement was performed at 
a temperature of $20-22{ }^{\circ} \mathrm{C}$. A value of urine specific gravity of less than $1.010 \mathrm{~g} / \mathrm{cm}^{3}$ may indicate an excessive fluid intake. A value higher than $1.020 \mathrm{~g} / \mathrm{cm}^{3}$ may indicate mild dehydration [14].

\section{Cognitive function}

The cognitive function was tested using the Mini Mental State Examination (MMSE), the Babcock Story Recall Test and the Trail Making Test (TMT) questionnaires. The Mini Mental State Examination (MMSE) is a 30-point questionnaire test that is commonly used to screen for cognitive impairment. It can be used to help diagnose dementia. The MMSE is a series of simple questions and problems in a number of different mental abilities, including a person's memory, orientation in time, registration, naming, reading, attention and language. A score of 28 points or above (out of 30) indicates normal cognition, between 24 and 27-MCI (mild cognitive impairment), and below 24 can indicate severe, moderate or mild dementia [15]. The Babcock Story Recall Test is a neuropsychological test of episodic memory. This is a 21-unit story measuring immediate and delayed recall. The total score ranges from 0 to 21 . The higher the score, the higher the level of episodic memory [16]. The Trail Making Test is a neuropsychological test of visual search speed, scanning, speed of processing, mental flexibility and executive. There are two parts of the test. Part A is used to examine cognitive processing speed. Test $\mathrm{B}$ is used to examine executive functioning. The result is the time to complete the task. The shorter the time, the better the cognitive function [17]. In all subjects, the questionnaire was filled in the same conditions (separate room), at the same time of the day, and by the same trained interviewer. The results were consulted with a psychologist.

\section{Geriatric Depression Scale—short form}

A short version of the GDS (GDS-SF) is a subset of 15 questions from the original GDS-LF with the highest correlation with depressive symptoms. The questions are answered 'yes' or 'no', and one point is assigned to each answer indicating depression. A score below or equal to 5 points is 'normal', a score above 5 points suggests depression, and a result above or equal to 10 points is almost always indicative of depression [18].

\section{Statistics}

The StatSoft Statistica software version 10.0. was used for the descriptive and statistical analyses. The results are reported as means \pm standard deviation (SD), as well as range or percentages. A $p$ value $\leq 0.05$ was considered statistically significant. Differences between groups were tested with the Chi-square test (nonparametric data) or the Student's $t$ test (parametric data). Pearson's correlation coefficients were used to test the relationship between the cognition function and the daily water intake or hydration status.

\section{Results}

The characteristics of the population under study were studied in relation to sex (Table 1). Of the 60 individuals, 16 (26.7\%) were men and 44 (73.3\%) were women. The mean age was $70.2 \pm 6.6$ years. The average body mass index was $27.1 \mathrm{~kg} / \mathrm{m}^{2}$, and most of the study population was overweight or obese ( $75 \%$ of the study population had a BMI $>25 \mathrm{~kg} /$ $\mathrm{m}^{2}$, data not given in the table). There were statistically significant differences observed between men and women concerning years of education, marital status, self-assessment of health status, presence of a cardiovascular disease, physical activity level, and dietary supplement usage. Table 2 shows the results of the cognitive function assessment tests and the screening test for depression in the study group. There were no statistically significant differences in the results of all cognitive function tests between genders. The average result of MMSE was $27.8 \pm 1.8$ points. Taking into account gender, a statistically significant difference was observed in the GDS results; the score was higher for women than for men, and for both groups, the mean value was within the 'normal' range (below 5 point). Table 3 shows the characteristics of the total study sample concerning factors connected with the hydration status: daily water intake and urine specific gravity. The mean daily water intake from all sources was $2441 \mathrm{ml}$, and as many as $70 \%$ of respondents met the reference values for an adequate intake (AI). Women were more likely to implement the recommendations at the AI level. Mean urine specific gravity amounted to $1.013 \mathrm{~g} / \mathrm{cm}^{3}$, which shows that the study population was in a good hydration state. There was a statistically significant difference in the specific gravity of urine depending on gender; men had a higher specific gravity of urine than women (which may be associated with a lower implementation of the recommendations for fluid intake by men).

Table 4 shows some additional factors connected with the hydration status: feeling of thirst, dryness in the mouth as well as feeling of refreshment after a drink. In the study group, $28.3 \%$ of the respondents reported incidents of incontinence related to activities, such as coughing, laughing or physical strain. Furthermore, $18.3 \%$ of the study group had problems with using the toilet and $10 \%$ intentionally limited the amount of beverages to reduce the number of times they visited the toilet. The majority of respondents felt thirsty at a moderate level (33.3\%) for most of the time, and as much as $23.3 \%$ did not feel thirsty at all. More than $80 \%$ of the participants did not feel a sensation of dryness in the mouth 
698

Aging Clinical and Experimental Research (2019) 31:695-703

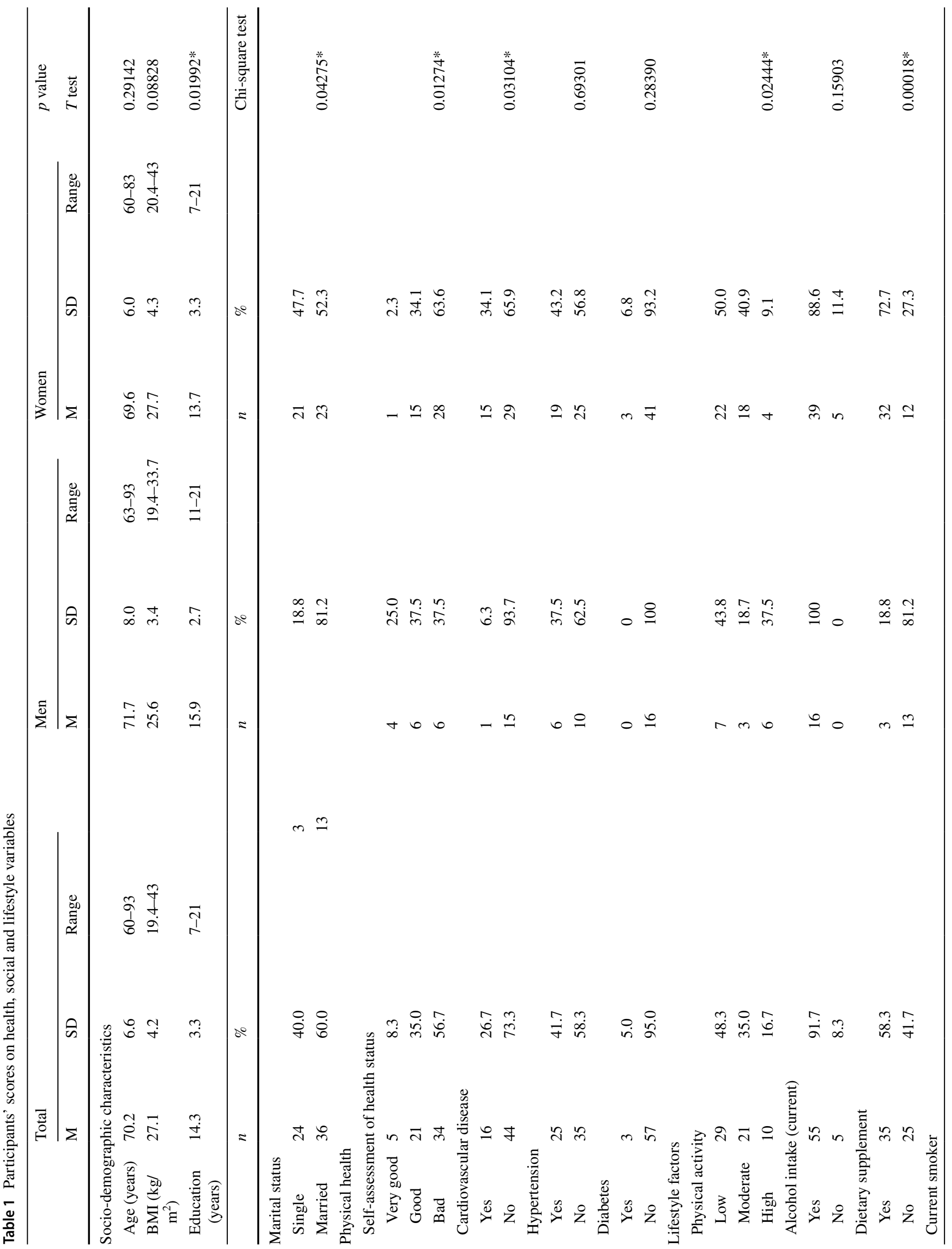

Springer 


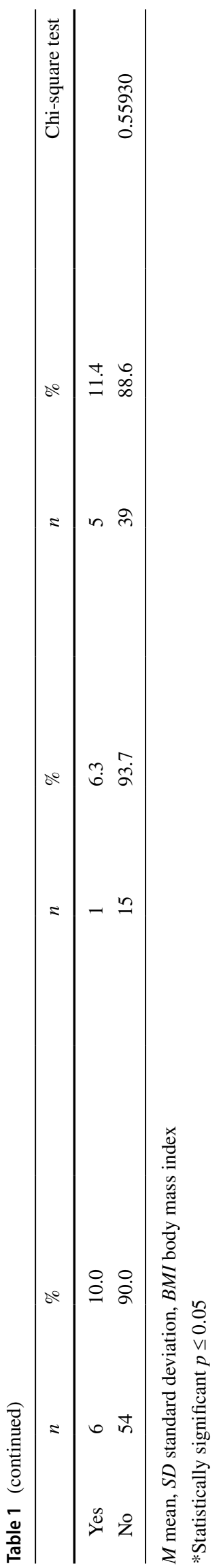

or felt it for a short period of time. Most respondents felt only slightly refreshed after a drink (33.3\%). Table 5 shows the characteristics of the respondents (socio-demographic, physical activity level, dietary supplementation, health status, daily water intake, urine specific gravity) in dependence of the results of MMSE. The study group was divided into two groups taking into account the score of the assessment test-participants with a score of 28 points or more (normal cognitive, $n=36$ ) as well as those with less than 28 points (cognitive impairment, $n=24$ ). There were no statistically significant differences between these two groups, with one exception - the number of years of education. A statistically, significantly higher percentage of subjects with a MMSE score of 28 points or more (normal cognitive) had a higher number of years of education than those with a score of less than 28 points ( $58.3 \%$ vs. $20.8 \%$, respectively). Correlations between the daily water intake/urine specific gravity as well as the results of cognitive and depression assessment tests are presented in Table 6 . We observed no statistically significant relationships between the daily water intake and the hydration status, measured as urine specific gravity and the cognitive function.

\section{Discussion and conclusions}

The elderly are considered to be an at-risk population regarding dehydration [5]. Existing evidence is strongly suggestive of high rates of dehydration in the elderly, especially within hospitals and residential care [19]. During hospitalisation, dehydration is independently associated with poorer outcomes, longer length of stay and greater costs [20]. Despite the general consensus that an appropriate level of fluid intake is essential for health [21], little work has been done to date to measure the relationship between fluid intake or the hydration status and the cognitive function. Existing data show that good hydration is connected with better results in cognitive tests, and mild dehydration can impair cognitive abilities [22], but there are only a few studies on the relation of the hydration status and the cognitive performance in elderly. In this study, the relationship between the hydration status and the cognitive performance has not been demonstrated, which is not consistent with the results of previous studies. The study conducted by Suhr et al. [23] on 28 healthy community-dwelling elderly demonstrated that a lower hydration status (defined as the total body water measured by the bioelectrical impedance method) was associated with a decreased psychomotor processing speed, poorer attention and memory. Another study by Suhr et al. [24] conducted on a group of 21 women (mean age of 60 years) showed a relation between the total body water (also measured by the bioelectrical impedance method) and working 
Table 2 Results of cognitive assessment tests and screening tests for depression in the study group

\begin{tabular}{|c|c|c|c|c|c|c|c|c|c|c|}
\hline \multirow[t]{2}{*}{ Variable/test name } & \multicolumn{3}{|l|}{ Total } & \multicolumn{3}{|l|}{ Men } & \multicolumn{3}{|c|}{ Women } & \multirow{2}{*}{$\begin{array}{l}p \text { value } \\
T \text { test }\end{array}$} \\
\hline & M & SD & Range & M & SD & Range & M & SD & Range & \\
\hline MMSE (pt.) & 27.8 & 1.8 & $22-30$ & 28.1 & 2.1 & $23-30$ & 27.7 & 1.7 & $22-30$ & 0.50092 \\
\hline Babcock Story Recall (pt.) & 9.4 & 3.1 & $4-17$ & 10.5 & 2.7 & $7-16$ & 9.0 & 3.1 & $4-17$ & 0.09454 \\
\hline Delayed recall of Babcock (pt.) & 13.4 & 3.8 & $6-21$ & 14.2 & 3.9 & $8-21$ & 13.1 & 3.8 & $6-12$ & 0.33227 \\
\hline TMT part A (sec.) & 44.5 & 14.8 & $21-98$ & 42.6 & 14.9 & $21-78$ & 45.2 & 14.9 & $25-98$ & 0.54248 \\
\hline TMT part B (sec.) & 109.3 & 51.6 & $42-321$ & 111.9 & 53.4 & $42-227$ & 108.4 & 51.5 & $45-321$ & 0.82675 \\
\hline GDS (pt.) & 3.5 & 2.7 & $0-12$ & 2.2 & 2.1 & $0-8$ & 3.9 & 2.8 & $0-12$ & $0.03050 *$ \\
\hline
\end{tabular}

$M$ mean, $S D$ standard deviation, MMSE Mini Mental State Examination, GDS Geriatric Depression Scale, TMT Trail Making Test, $p t$. points, sec. seconds

*Statistically significant $p \leq 0.05$

Table 3 Daily water intake, energy value of the diet, and urine specific gravity in a study sample

\begin{tabular}{|c|c|c|c|c|c|c|c|c|c|c|}
\hline \multirow[t]{2}{*}{ Characteristic } & \multicolumn{3}{|l|}{ Total } & \multicolumn{3}{|l|}{ Men } & \multicolumn{3}{|c|}{ Women } & \multirow{2}{*}{$\begin{array}{l}p \text { value } \\
T \text { Test }\end{array}$} \\
\hline & M & SD & Range & M & SD & Range & M & SD & Range & \\
\hline \multicolumn{11}{|c|}{ Data on water consumption evaluated on a 3-day record } \\
\hline Daily water intake (ml/day) & 2441 & 622 & $982-4326$ & 2665 & 725 & $1701-4326$ & 2360 & 567 & $982-3841$ & 0.09357 \\
\hline \multirow[t]{2}{*}{ Daily calories intake (kcal/day) } & 1731 & 442 & $511-2571$ & 2084 & 341 & $1398-2571$ & 1603 & 405 & $511-2485$ & $0.00008^{*}$ \\
\hline & $n$ & $\%$ & & $n$ & $\%$ & & $n$ & $\%$ & & Chi-square test \\
\hline \multicolumn{11}{|c|}{ Water consumption above the level of the AI } \\
\hline Yes & 42 & 70.0 & & 8 & 50.0 & & 34 & 77.3 & & \\
\hline \multirow[t]{2}{*}{ No } & 18 & 30.0 & & 8 & 50.0 & & 10 & 22.7 & & $0.04149 *$ \\
\hline & M & SD & Range & M & SD & Range & M & SD & Range & $T$ Test \\
\hline \multicolumn{11}{|l|}{ Urine parameters } \\
\hline Urine specific gravity $\left(\mathrm{g} / \mathrm{cm}^{3}\right)$ & 1.013 & 0.005 & $1.004-1.025$ & 1.016 & 0.005 & $1.009-1.024$ & 1.012 & 0.0044 & $1.004-$ & $250.00223 *$ \\
\hline
\end{tabular}

$M$ mean, $S D$ standard deviation, $A I$ reference values for adequate intake (2000 $\mathrm{ml}$ for women and $2500 \mathrm{ml}$ for men)

*Statistically significant $p \leq 0.05$

memory or memory skills. Another study, which examined the effect of age on energy balance, metabolism, hydration and performance during 10 days of strenuous hill walking, showed that the younger group (mean age of 24 years) remained hydrated, whereas the older group became progressively dehydrated (mean age of 56 years). The increased urine osmolality in the older group was correlated with a decline in choice reaction times [25]. It needs to be highlighted that the present study also included seemingly healthy elderly, but the result indicated that the hydration status of individuals was proper; none of the participants were assessed as mild or severely dehydrated. Despite this, men had a statistically significant higher specific gravity of urine than women and less often implemented the recommendations for fluid intake, which is consistent with the literature [26]. Furthermore, a significant percentage of the participants did not feel a sensation of dryness in the mouth or felt it for a short period of time, and for most of time, the majority of the respondents felt thirsty at a moderate level or did not feel thirsty at all.

Some methodological weaknesses of this type of research should be considered, such as different measurements in the cognitive assessment and the hydration state, and a relatively small sample size. Most studies on hydration and the cognitive function are short term and it is not certain if there are longer term cognitive decrements resulting from dehydration. The study by Pross et al. [27] on a group of young, healthy women suggests that even after replenishing a fluid deficit, effects on mood may persist. In view of the fact that the cognitive functioning may still be compromised in young people even after achieving euhydration, the elderly 
Table 4 Characteristics of total study sample for factors connected with hydration status

\begin{tabular}{|c|c|c|c|c|c|c|c|}
\hline \multirow[t]{2}{*}{ Characteristic } & \multicolumn{2}{|c|}{ Total } & \multicolumn{2}{|c|}{ Men } & \multicolumn{2}{|c|}{ Women } & \multirow{2}{*}{$\begin{array}{l}p \text { value } \\
\text { Chi-square test }\end{array}$} \\
\hline & $n$ & $\%$ & $n$ & $\%$ & $n$ & $\%$ & \\
\hline \multicolumn{8}{|l|}{ Feeling dizzy } \\
\hline Yes & 14 & 23.3 & 1 & 6.3 & 13 & 29.5 & \\
\hline No & 46 & 76.7 & 15 & 93.7 & 31 & 70.5 & 0.05921 \\
\hline \multicolumn{8}{|l|}{ Headaches } \\
\hline Yes & 22 & 36.7 & 3 & 18.7 & 19 & 43.2 & \\
\hline No & 38 & 63.3 & 13 & 81.3 & 25 & 56.8 & 0.08245 \\
\hline \multicolumn{8}{|l|}{ Feel weak } \\
\hline Most of the time & 4 & 6.6 & 0 & 0 & 4 & 9.1 & \\
\hline Some time & 9 & 15.0 & 0 & 0 & 9 & 20.5 & \\
\hline Insignificant part of time & 31 & 51.7 & 10 & 62.5 & 21 & 47.7 & \\
\hline Never & 16 & 26.7 & 6 & 37.5 & 10 & 22.7 & 0.10303 \\
\hline \multicolumn{8}{|c|}{ Incontinence during the coughing, laughing, physical strain } \\
\hline Yes & 17 & 28.3 & 2 & 12.5 & 15 & 34.1 & \\
\hline No & 43 & 71.7 & 14 & 87.5 & 29 & 65.9 & 0.10075 \\
\hline \multicolumn{8}{|l|}{ Feeling dryness in the mouth } \\
\hline Most of the time & 3 & 5.0 & 0 & 0 & 3 & 6.8 & \\
\hline Some time & 9 & 15.0 & 0 & 0 & 9 & 20.5 & \\
\hline Insignificant part of time & 29 & 48.3 & 11 & 68.7 & 18 & 40.9 & \\
\hline Never & 19 & 31.7 & 5 & 31.3 & 14 & 31.8 & 0.10021 \\
\hline \multicolumn{8}{|l|}{ Feeling of thirst } \\
\hline Not at all & 14 & 23.3 & 6 & 37.5 & 8 & 18.2 & \\
\hline Very gentle & 13 & 21.7 & 1 & 6.3 & 12 & 27.3 & \\
\hline Mild & 13 & 21.7 & 4 & 25.0 & 9 & 20.5 & \\
\hline Average & 20 & 33.3 & 5 & 31.2 & 15 & 34.0 & 0.22043 \\
\hline \multicolumn{8}{|c|}{ Refreshment after drinking fluids } \\
\hline Not at all or a little & 25 & 41.7 & 4 & 25.0 & 21 & 47.7 & \\
\hline Average & 16 & 26.6 & 5 & 31.3 & 11 & 25.0 & \\
\hline Enough & 19 & 31.7 & 7 & 43.7 & 12 & 27.3 & 0.26815 \\
\hline \multicolumn{8}{|c|}{ Consciously limiting fluid intake to avoid visiting the toilet } \\
\hline Yes & 6 & 10.0 & 0 & 0 & 6 & 13.6 & \\
\hline No & 54 & 90.0 & 16 & 100 & 38 & 86.4 & 0.11947 \\
\hline
\end{tabular}

*Statistically significant $p \leq 0.05$ are possibly more exposed to the negative effects of dehydration; however, there is a need for additional research in this area.

It is necessary to replicate the findings of this study with a larger and more diverse sample of older adults. The assessment of hydration is very difficult; the authors of several published review papers claim that a single gold standard for hydration assessment is not possible [2].
In the present study, the hydration status was tested by evaluating urine specific gravity. This method is simple, fast, non-invasive and cheap, so it gives the possibility to use it in large epidemiological studies. It is necessary to develop ways of screening for mild dehydration and recognise the early symptoms leading to dehydration to prevent severe dehydration and its consequences. The relationship between hydration and cognitive performance is an emerging area of study, which requires more research. 
Table 5 Differences between group with MMSE score above or below the normal range (MMSE $\geq 28$ point), depending on the sociodemographic characteristics, lifestyle and factors connected with hydration status

\begin{tabular}{|c|c|c|c|}
\hline \multirow[t]{3}{*}{ Characteristic } & \multicolumn{2}{|c|}{ MMSE score } & \multirow{3}{*}{$\begin{array}{l}\text { Chi-square test } \\
p\end{array}$} \\
\hline & $\begin{array}{l}\geq 28, \\
n=36\end{array}$ & $\begin{array}{l}<28, \\
n=24\end{array}$ & \\
\hline & $n \quad \%$ & $n \quad \%$ & \\
\hline
\end{tabular}

\section{Gender}

$\begin{array}{lrrrrr}\text { Men } & 11 & 30.6 & 5 & 20.8 & \\ \text { Women } & 25 & 69.4 & 19 & 79.2 & 0.40412 \\ \text { Age (years) } & & & & & \\ 60-70 & 20 & 55.6 & 14 & 58.3 & \\ 71-93 & 16 & 44.4 & 10 & 41.7 & 0.83155 \\ \text { BMI }\left(\mathrm{kg} / \mathrm{m}^{2}\right) & & & & & \\ 18.5-24.9 & 11 & 30.6 & 4 & 16.7 & \\ 25.0-29.9 & 18 & 50.0 & 16 & 66.6 & \\ \geq 30 & 7 & 19.4 & 4 & 16.7 & 0.39110\end{array}$

Education (years)

$\begin{array}{lrrrrr}\leq 14 & 15 & 41.7 & 19 & 79.2 & \\ >14 & 21 & 58.3 & 5 & 20.8 & 0.00408^{*} \\ \begin{array}{l}\text { Marital status } \\ \quad \text { Single }\end{array} & 14 & 38.9 & 10 & 41.7 & \\ \quad \text { Married } & 22 & 61.1 & 14 & 58.3 & 0.82964 \\ \text { Physical activity } & & & & & \\ \quad \text { Low } & 16 & 44.4 & 13 & 54.2 & \\ \quad \text { Moderate } & 14 & 38.9 & 7 & 29.2 & \\ \quad \text { High } & 6 & 16.7 & 4 & 16.6 & 0.71516\end{array}$

Dietary supplementation (the last month)

$\begin{array}{llllll}\text { Yes } & 23 & 63.9 & 12 & 50 & \\ \text { No } & 13 & 36.1 & 12 & 50 & 0.28505\end{array}$

Self-assessment of health status

$\begin{array}{lrrrrr}\text { Very good } & 3 & 8.3 & 2 & 8.3 & \\ \text { Good } & 13 & 36.1 & 8 & 33.3 & \\ \text { Bad } & 20 & 55.6 & 14 & 58.4 & 0.97465\end{array}$

Daily water intake above AI

$\begin{array}{lrrrrr}\text { Yes } & 25 & 69.4 & 17 & 70.8 & \\ \text { No } & 11 & 30.6 & 7 & 29.2 & 0.90844 \\ \text { Urine specific gravity } & & & & & \\ \leq 1.010 \mathrm{~g} / \mathrm{cm}^{3}(n=21) & 10 & 27.8 & 11 & 45.8 & \\ 1.011-1.014 \mathrm{~g} / \mathrm{cm}^{3}(n=20) & 11 & 30.5 & 9 & 37.5 & \\ >1.014 \mathrm{~g} / \mathrm{cm}^{3}(n=19) & 15 & 41.7 & 4 & 16.7 & 0.11126\end{array}$

$A I$ reference values for adequate intake $(2000 \mathrm{ml}$ for women and $2500 \mathrm{ml}$ for men), BMI body mass index, MMSE Mini Mental State Examination

*Statistically significant $p \leq 0.05$

Future studies should consider an evaluation of water consumption and the state of hydration for longer periods of time to determine whether hydration enhancement leads to improvements in cognitive performance.
Table 6 Correlations between daily water intake as well as urine specific gravity and cognitive and depression assessment tests

\begin{tabular}{|c|c|c|c|c|}
\hline \multirow[t]{2}{*}{ Variable/test name } & \multicolumn{2}{|c|}{ Daily water intake } & \multicolumn{2}{|c|}{$\begin{array}{l}\text { Urine specific } \\
\text { gravity }\end{array}$} \\
\hline & $r$ & $p$ & $r$ & $p$ \\
\hline MMSE (pt.) & 0.15777 & 0.246 & 0.17034 & 0.209 \\
\hline Babcock Story Recall (pt.) & 0.09455 & 0.488 & -0.01062 & 0.938 \\
\hline $\begin{array}{l}\text { Delayed Recall of Babcock } \\
\text { (pt.) }\end{array}$ & 0.01930 & 0.888 & 0.04882 & 0.721 \\
\hline TMT part A (sec) & -0.11535 & 0.397 & -0.19221 & 0.156 \\
\hline TMT part B (sec.) & -0.18781 & 0.166 & -0.16226 & 0.232 \\
\hline GDS (pt.) & -0.19743 & 0.145 & -0.12706 & 0.351 \\
\hline
\end{tabular}

MMSE Mini Mental State Examination, GDS Geriatric Depression Scale, TMT Trail Making Test, $p t$. points, sec. seconds, $r$ Pearson correlation coefficient

*Statistically significant $p \leq 0.05$

\section{Compliance with ethical standards}

Conflict of interest The corresponding author received a grant for research from the International Chair of Advanced Studies on Hydration (CIEAH). The other authors declare that they have no conflict of interest.

Ethical approval This study was approved by a local ethical committee and was performed in accordance with the Helsinki Declaration and its later amendments.

Informed consent Informed consent was obtained from all individual participants included in the study.

Open Access This article is distributed under the terms of the Creative Commons Attribution 4.0 International License (http://creativeco mmons.org/licenses/by/4.0/), which permits unrestricted use, distribution, and reproduction in any medium, provided you give appropriate credit to the original author(s) and the source, provide a link to the Creative Commons license, and indicate if changes were made.

\section{References}

1. Sawka MN, Cheuvront SN, Carter R (2005) Human water needs. Nutr Rev 63:S30-S39. https://doi.org/10.1301/nr.2005.jun. S30-S39

2. Armstrong LE (2007) Assessing hydration status: the elusive gold standard. J Am Coll Nutr 26:575s-584s

3. Lancaster KJ, Smiciklas-Wright H, Heller DA, Ahern FM, Jensen G (2003) Dehydration in black and white older adults using diuretics. Ann Epidemiol 13:525-529

4. Taniguchi H, Akiyama M, Gomi I, Kimura M (2015) Development of a pre-dehydration assessment sheet: research among elderly individuals who regularly visited an elderly-care institution. Nihon Ronen Igakkai Zasshi 52:359-366. https://doi. org/10.3143/geriatrics.52.359 
5. Hooper L, Bunn D, Jimoh FO et al. (2014) Water-loss dehydration and aging. Mech Ageing Dev 136-137:50-58. https://doi. org/10.1016/j.mad.2013.11.009

6. Begum MN, Johnson CS (2010) A review of the literature on dehydration in the institutionalized elderly. e-SPEN Eur J Clin Nutr Metab 5:e47-e53

7. Lieberman HR (2007) Hydration and cognition: a critical review and recommendations for future research. J Am Coll Nutr 26:555S-561S

8. Lin LC, Watson R, Wu SC (2010) What is associated with low food intake in older people with dementia? J Clin Nurs 19:5359. https://doi.org/10.1111/j.1365-2702.2009.02962.x

9. Wu MS, Lan TH, Chen CM et al. (2011) Socio-demographic and health-related factors associated with cognitive impairment in the elderly in Taiwan. BMC Public Health 11:1-8. https://doi. org/10.1186/1471-2458-11-22

10. Vivanti A, Harvey K, Ash S (2010) Developing a quick and practical screen to improve the identification of poor hydration in geriatric and rehabilitative care. Arch Gerontol Geriatr 50:156-164. https://doi.org/10.1016/j.archger.2009.03.003

11. WHO (2000) Obesity: preventing and managing the global epidemic. Report of a WHO Consultation. WHO Technical Report Series 894. World Health Organization, Geneva

12. Kunachowicz H, Nadolna I, Przygoda B et al (2005) Tabele składu i wartości odżywczej żywności [Data base 'Tables of nutritional value of food products and dishes']. Wydawnictwo Lekarskie PZWL (in Polish), Warsaw

13. Jarosz M, Szponar L, Rychlik E et al (2012) Woda i elektrolity [Water and electrolytes]. In: Jarosz M (ed) Normy żywienia dla populacji polskiej—nowelizacja [Nutrition standards for the Polish population-amendment]. National Food and Nutrition Institute in Polish), Warsaw, pp 143-153

14. Simerville JA, Maxted WC, Pahira JJ (2005) Urinalysis: a comprehensive review. Am Fam Phys 71:1153-1162

15. Folstein MF, Folstein SE, McHugh PR (1975) "Mini-mental state". A practical method for grading the cognitive state of patients for the clinician. J Psychiatr Res 12(3):189-198

16. Babcock H, Levy L (1940) The measurement of efficiency of mental functioning (revised examination): test and manual of directions. C. H. Stoelting, Chicago
17. Reitan RM (1958) Validity of the trail making test as an indicator of organic brain damage. Percept Motor Skills 3:271-276

18. Sheikh JI, Yesavage JA (1985) Geriatric Depression Scale (GDS): recent evidence and development of a shorter version. Clin Gerontol 1/2:165-173

19. Hooper L (2016) Why, oh why, are so many older adults not drinking enough fluid? J Acad Nutr Diet 116:774-778. https:// doi.org/10.1016/j.jand.2016.01.006

20. El-Sharkawy AM, Sahota O, Maughan RJ et al (2014) The pathophysiology of fluid and electrolyte balance in the older adult surgical patient. Clin Nutr 33:6-13. https://doi.org/10.1016/j. clnu.2013.11.010

21. Popkin BM, D’Anci KE, Rosenberg IH (2010) Water, hydration, and health. Nutr Rev 68:439-458. https://doi.org/10.111 1/j.1753-4887.2010.00304.x

22. Masento NA, Golightly M, Field DT et al (2014) Effects of hydration status on cognitive performance and mood. Br J Nutr 111:1841-1852. https://doi.org/10.1017/S0007114513004455

23. Suhr JA, Hall J, Patterson SM et al (2004) The relation of hydration status to cognitive performance in healthy older adults. Int J Psychophysiol 53:121-125. https://doi.org/10.1016/j.ijpsy cho.2004.03.003

24. Suhr JA, Patterson SM, Austin AW, Heffner KL (2010) The relation of hydration status to declarative memory and working memory in older adults. J Nutr Health Aging 14:840-843

25. Ainslie PN, Campbell IT, Frayn KN et al (2002) Energy balance, metabolism, hydration, and performance during strenuous hill walking: the effect of age. J Appl Physiol (1985) 93:714-723. https://doi.org/10.1152/japplphysiol.01249.2001

26. Ferreira-Pego C, Guelinckx I, Moreno LA et al (2015) Total fluid intake and its determinants: cross-sectional surveys among adults in 13 countries worldwide. Eur J Nutr 54:35-43. https://doi. org/10.1007/s00394-015-0943-9

27. Pross N, Demazieres A, Girard N et al (2013) Influence of progressive fluid restriction on mood and physiological markers of dehydration in women. Br J Nutr 109:313-321. https://doi. org/10.1017/S0007114512001080 